\title{
Discussion about the Intensity of Fire Rescue Training in Miaoli County
}

\author{
Hung-Teng Chang \\ Assistant Professor, Yu-Da University of Science and Techenology \\ No. 168, Hsueh-fu Rd., Tanwen Village, Chaochiao Township \\ Miaoli County, 361 Taiwan, (R.O.C) \\ cht@ydu.edu.tw \\ Pin-Chang Chen \\ Assistant Professor, CTBC Financial Management College \\ No.600, Sec. 3, Taijiang Blvd., Annan Dist., Tainan City 709, Taiwan (R.O.C.) \\ chenpc@ctbc.edu.tw

\section{Chih-Yi Ho*} \\ Postgraduate, Yu-Da University of Science and Techenology \\ No. 168, Hsueh-fu Rd., Tanwen Village, Chaochiao Township \\ Miaoli County, 361 Taiwan, (R.O.C). \\ *williamslift@gmail.com
}

\begin{abstract}
Along with the abnormalities of global climate, the changes of social patterns, and the increasing and more complex damage caused by disasters, it is extremely challenging for firefighters to take right actions, adopt appropriate strategies to integrate relief resources, and complete tasks safely, accurately, and fast in the face of disasters.

This study explored the performance of the fire rescue team of Miaoli County Government after training. First, it probed into the enhancement of individual strengthen and tactics and rescue teamwork. Then, based on literature review, it set up a framework, carried out questionnaires of experts twice with Delphi Method to establish the aspects for assessment, regarded the students of Phase III rescue training of Miaoli County Fire Bureau as its subjects, employed analytic hierarchy process (AHP) and considered the needs of coaches and the actual situation of local disaster to understand the degrees of importance attached to the aspects, and identify important factors to assess the quality of training of the rescue team.

Lastly, it offered suggestions for improvement of the rescue team and the curriculum to the Training Department of Miaoli County Fire Bureau so as to improve the quality offirefighters and make them complete relief mission and other tasks more safely and efficiently.
\end{abstract}

Ke ywords : fire rescue training, quality of training, Delphi Method, AHP

\section{INTRODUCTION}

Along with the abnormalities of global climate and the changes of social patterns, disasters are becoming stronger and more complex. Hence, it is vital to enhance the fire fighting capability and disaster relief through professional training, wherein, the training of fire rescue team is an essential indicator. The training shall be more professional, efficient, and institutionalized so that firefighters may complete their relief mission and other tasks more safely and efficiently.

This study adopted "AHP" and a questionnaire based on "Modified Delphi Method" to analyze the intensity of fire rescue training in Miaoli, explore the conformance of the intensity to students' psychological quality and skill development so as to plan the training targeting at the existing issues and needs of the disasters in Miaoli and propose specific suggestions to Miaoli County Fire Bureau as the reference for the curriculum planning of rescue team. 


\section{LITERATURE REVIEW}

Based on a preliminary analysis of literature, this study mainly reviewed the literature on "relevant existing regulations of fire rescue training", "training quality and effectiveness", "Delphi Method", and "AHP".

\subsection{The Significance of Rescue Team Training}

Currently, the fire bureaus of the counties in Taiwan organize rescue team and faculty training on their own based on [1] National Fire Agency (85) Letter (1996) Hsiao-Shu-Jiu-Tze-\# 8550146 issued on February 8, 1996 by National Fire Agency and National Fire Agency Letter (2000) Hsiao-Shu-Jiu-Tze\# 89F0354 issued on June 30, 2000, a corrected version of the former, grant certificates respectively, and hold refreshment annually.

"On-the-job training" is one of the main approaches not weed out by trends [2]. Rescue training is critical for the firefighting career of firefighters, as it exerts high physical and psychological pressure and brings about substantial improvement. [3] assumed that firefighters, no matter male or female, improved significantly after training which brought about great help to their practical work and disaster relief. Also, [4] study deemed that the higher awareness of teamwork after training of the students, the better their teamwork, "teamwork knowledge", and "team behavior" are, while their "self-efficiency" and "participation motive" has no effect on their training effectiveness. [5] indicated that the physical fitness test results showed significantly improvement of the students during and after training, which were better than those before training. And their improvement resulted in good help in practical disaster relief. The correct sport awareness they learned not only prevented them from sport injury, but also help them combine physical fitness with skill to reach the goals of training. When most of them had basic rescue skills, they could complement each other at work so as to reduce the risks to the lives of them and others and prove the significance of training [6]. Therefore, fire rescue training stands for the spirit, acknowledge, and glory of fire fighting.

On the spot of disaster rescue, firefighters face various pressure and challenges, so they not only need to have courage and spirit of adventure, but also race against time in each task. To complete tasks quickly and reliably is inseparable from usual training of basic combat skills and development of physical agility [7]. According to strategic training, reasonable training processes include: 1) To determine the needs and priority of training; 2) To decide training targets and plan basics; 3) To select a training program and perform it sequentially; 4) To implement the training program with both hardware and software; 5) To evaluate effectiveness and feedback to improve [8]. Hence, rescue team training shall improve the effectiveness of the training of firefighters via complete education and training system.

The analysis of [9] showed that $80 \%$ firefighters believed that rescue team training was necessary to cope with the implementation of various tasks in practice, while the curriculum shall center on appliance applications, rescue skills, ropes application, and other professional courses.

\subsection{Delphi Method}

It is an analytical method first applied in 1948 by Rand Corporation in a research of national defense and military named "Project Delphi" sponsored by United States Air Force. Based on the joint anticipation and consensus by an expert group, it served as a reference for decision-makers. The experts had the consensus through constant written communication and expression of opinions. Due to the influences by the factors like time, manpower, and funds, the consensus was modified or deleted to push the research forward smoothly, known as "Modified Delphi Method" [10].

\subsection{AHP}

AHP was proposed by Saaty [11] in 1971, who suggested that this method could be applied in 12 types of issues: optimize, plan, and generate a variety of alternatives, predict output or assess risks, set priorities, choose the best plans, allocate resources, design systems, measure performances, validate system stability, resolve conflicts, and identify needs.

\section{RESEARCH METHOD}

\subsection{Research Process}

This study adopted both qualitative and quantitative methods: Based on domestic and foreign literature review, it carried out a questionnaire with "Modified Delphi Method", established a decision 
hierarchical structure impacting fire rescue training quality by rescue training coaches (who had the Certificate of Qualification issued by National Fire Agency), used "AHP" to confirm the weight of each indicator and sort them, and provide suggestions to improve fire rescue training courses to the Training Department of Miaoli County Fire Bureau as their reference. Meanwhile, it served as a reference for the coaches of the Bureau so that they could enhance the quality of their students more effectively.

\subsection{Research Subjects}

1. Stage 1: 14 experts completed the questionnaire based on Delphi Method (Coaches of Miaoli County Fire Rescue Team).

2. Stage 2: 40 experts completed the questionnaire based on AHP (Students of Miaoli County Fire Rescue Team).

\subsection{Research Procedures and Implementation}

In consideration of historical backgrounds and geography, the intensity of fire rescue training of various regions varies. This study, based on the meeting outcome of the coaches of Phase III fire rescue training of Miaoli County Fire Bureau and literature analysis, preliminarily regarded "the improvement of individual tactics and skills" and "teamwork" as the two main aspects influencing the intensity of fire rescue training in Miaoli County.

1. The improvement of individual tactics and skills refers to: application of ropes and equipment, skills, physical strength, safety awareness, and needs of new rescue equipment.

2. Teamwork refers to: special disaster rescue, team training, awareness of system framework, leadership and governing, courage and discipline, and heroic quality.

Then, it used Modified Delphi Method to conduct a questionnaire to the experts so as to preliminarily confirm the appropriateness of the project. The standard to delete questions in the first round of questionnaire with Modified Delphi Method of experts was 75\%. 14 copies of the questionnaire were sent with a response rate of $100 \%$. The first round of questionnaire was described below:

The average values of Aspect 1 (Needs of new rescue equipment) and Aspect 2 (Heroism) were lower than 3.5 points $(75 \%)$, while the standard deviation of Aspect 1 (Needs of new rescue equipment) was greater than 1 . Thus, this study removed the two decision-making items. No other factors were added since no experts did so in the questionnaire.

The second round of questionnaire was developed based on the deletion of the first. The standard to delete questions in the second round of questionnaire with Modified Delphi Method of experts was $80 \%$. 14 copies of the questionnaire were sent with a response rate of $100 \%$. The second round of questionnaire was described below:

The standard deviations were lower than 1 , which means the experts had reached a consensus. And the average values were more than $4(80 \%)$. Thus, the 10 decision-making items received high recognition from the experts with support rates over $80 \%$. The decision-making framework was decided accordingly. This study referred to "typical AHP chart" [12] to design the decision-making hierarchical chart:

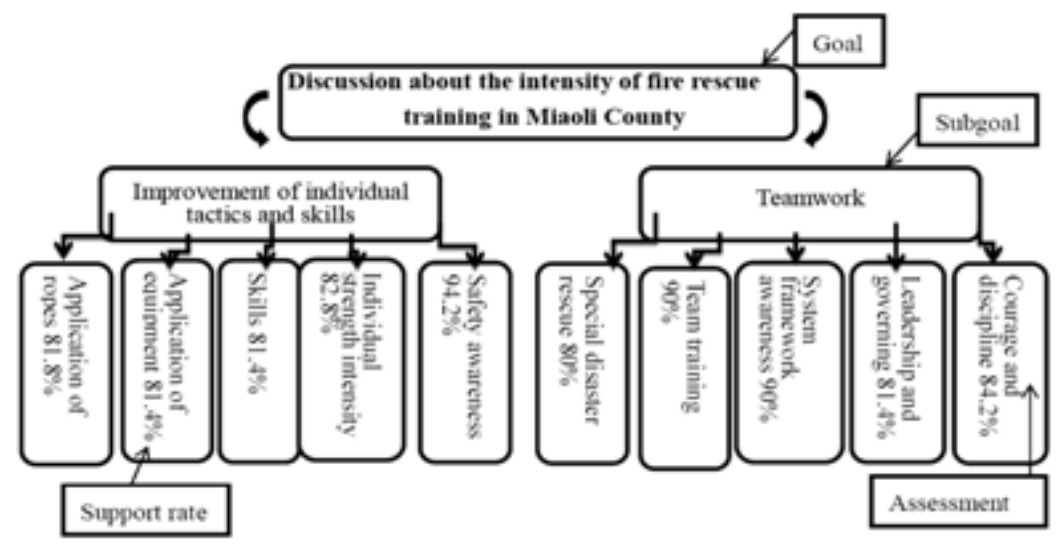

Based on the above hierarchical framework, the key points of each assessment item are summarized in Table 1: 
Table1. Description of the decision-making items influencing the intensity of fire rescue training in Miaoli County

\begin{tabular}{|c|c|c|}
\hline \multicolumn{2}{|c|}{ Ass essment Item } & Key Points \\
\hline \multirow{5}{*}{ 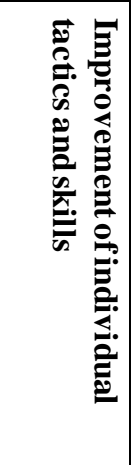 } & Application of ropes & Application of basic ropes, bas ic setup of ropes, and setup of tight ropes. \\
\hline & $\begin{array}{l}\text { Application of } \\
\text { equipment }\end{array}$ & $\begin{array}{l}\text { Proficiency of relevant rescue equipment and understanding of technical } \\
\text { specifications of the equipment. }\end{array}$ \\
\hline & Skills & $\begin{array}{l}\text { Lowering of ropes: seat-style, front-style, carrying people on the back, carrying } \\
\text { people in front; Rope crossing: horizontal, monkey-style, backward, and self-help } \\
\text { method; and Ropes climbing: hand, one foot and both feet, application of rise } \\
\text { equipment, application of binodal ladder. }\end{array}$ \\
\hline & $\begin{array}{l}\text { Individual strength } \\
\text { intensity }\end{array}$ & $\begin{array}{l}\text { Intensive training of endurance, weight, and physical fitness: Running with air } \\
\text { bottle, beach running, climbing ladder with load, tactics, physical strength, etc. }\end{array}$ \\
\hline & Safety awarenes s & $\begin{array}{l}\text { Risk control and as sessment and precautionary meas ures. Excluding or } \\
\text { strengthening the possibilities of risk factors. }\end{array}$ \\
\hline \multirow{5}{*}{ 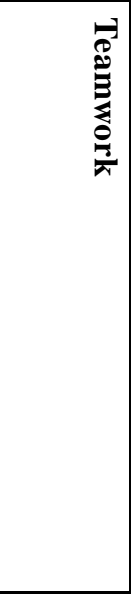 } & Special dis aster rescue & $\begin{array}{l}\text { Profes sional training of water rescue, surf rescue, boat rescue, mountain rescue, } \\
\text { fire rescue, and search-and-rescue. }\end{array}$ \\
\hline & Team training & $\begin{array}{l}\text { Training tasks to be completed with several people: fixation of stretcher, rescue of } \\
\text { low positions, fire-ground searching methods (two people method, three people } \\
\text { method), horizontal underground tunnel rescue, high-rise rescue, and helicopter } \\
\text { joint rescue. }\end{array}$ \\
\hline & $\begin{array}{l}\text { Systemframework } \\
\text { awareness }\end{array}$ & $\begin{array}{l}\text { Selection of fixation points of rope systemand application of component force, } \\
\text { RPM systemconversion and application of alternative equipment, and rope safety } \\
\text { factor and angles. }\end{array}$ \\
\hline & $\begin{array}{l}\text { Leadership and } \\
\text { governing }\end{array}$ & $\begin{array}{l}\text { Organizational skills and leadership not fooled by views, right judgment at the } \\
\text { appropriate time, persuasion or guiding of others, and control of the whole } \\
\text { dis aster site. }\end{array}$ \\
\hline & Courage and discipline & $\begin{array}{l}\text { Perseverance and discipline are the heritage of a rescue teamand the soul of } \\
\text { rescue. }\end{array}$ \\
\hline
\end{tabular}

\section{EMPIRICAL AND RESULTS ANALYSIS}

This chapter developed an AHP questionnaire based on the framework defined above. 40 copies of the questionnaire were sent, while 40 effective copies were collected with a response rate of $100 \% .35$ copies were sent to male students, while 5 to female. The results are described as follows based on the analysis of the data with "Expert Choice":

The discussion results of the aspects of the intensity of fire rescue training in Miaoli show that the weights of "improvement of individual tactics and skills" and "teamwork" are 0.673 and 0.327 , respectively. Below are their decision-making items:

1. Improvement of individual tactics and skills: Application of ropes (0.297) $>$ application of equipment $(0.260)>\operatorname{skills}(0.191)>$ safety awareness $(0.140)>$ physical strength $(0.112)$.

2. Teamwork: Special disaster rescue $(0.308)>$ team training $(0.270)>$ awareness of system framework $(0.221)>$ leadership and governing $(0.116)$ courage and discipline $(0.085)$.

The weight and assessment of decision-making items is shown in Table 2:

Table2. Weight and assessment of decision-making items

\begin{tabular}{|c|c|c|c|c|c|c|}
\hline Goal & \multicolumn{3}{|c|}{ Classification/Weight/Rank } & \multicolumn{3}{|l|}{ Guideline--- } \\
\hline \multirow{10}{*}{ 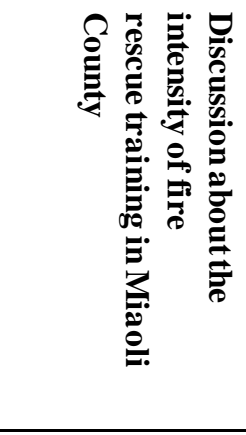 } & \multirow{5}{*}{$\begin{array}{l}\text { Improvement of } \\
\text { individual tactics } \\
\text { and skills }\end{array}$} & \multirow[t]{5}{*}{0.673} & \multirow[t]{5}{*}{1} & Application of ropes & 0.297 & 1 \\
\hline & & & & Application of equipment & 0.260 & 2 \\
\hline & & & & Skills & 0.191 & 3 \\
\hline & & & & Physicalstrength & 0.112 & 5 \\
\hline & & & & Safety awareness & 0.140 & 4 \\
\hline & \multirow[t]{5}{*}{ Teamwork } & \multirow[t]{5}{*}{0.327} & \multirow[t]{5}{*}{2} & Special disaster rescue & 0.308 & 1 \\
\hline & & & & Team training & 0.270 & 2 \\
\hline & & & & Awareness of systemframework & 0.221 & 3 \\
\hline & & & & Leadership and governing & 0.116 & 4 \\
\hline & & & & Courage and discipline & 0.085 & 5 \\
\hline
\end{tabular}

3. The overall assessment of the factors shows that the rank of the items is application of ropes $(0.200)$ $>$ application of equipment $(0.175)>$ skills $(0.129)>$ special disaster rescue $(0.101)>$ safety 
awareness $(0.094)$. The five decision-making items account for $70 \%$. These are the items/courses attached with great importance by the students. The items ranked from sixth to tenth are team training (0.088), individual physical strength (0.075), system framework awareness (0.072), leadership and governing (0.038), and courage and discipline (0.028). They account for $30 \%$. These are the items/courses attached with medium importance by the students. The degree of importance and overall weight analysis is displayed in Table 3:

Table3. Analysis of the degree of importance attached to the decision-making items by the students receiving rescue training

\begin{tabular}{|c|c|c|c|c|}
\hline $\begin{array}{l}\text { Weight in } \\
\text { Order }\end{array}$ & $\begin{array}{l}\text { Degree of } \\
\text { Importance }(\%)\end{array}$ & Decision-making Items & Weight & Aspects \\
\hline 1 & \multirow[t]{5}{*}{$\begin{array}{l}\text { High importance } \\
(70 \%)\end{array}$} & Application of ropes & 0.200 & $\begin{array}{l}\text { Improvement of individual } \\
\text { tactics and skills }\end{array}$ \\
\hline 2 & & Application of equipment & 0.175 & $\begin{array}{l}\text { Improvement of individual } \\
\text { tactics and skills }\end{array}$ \\
\hline 3 & & Skills & 0.129 & $\begin{array}{l}\text { Improvement of individual } \\
\text { tactics and skills }\end{array}$ \\
\hline 4 & & Special disaster rescue & 0.101 & Teamwork \\
\hline 5 & & Safety awareness & 0.094 & $\begin{array}{l}\text { Improvement of individual } \\
\text { tactics and skills }\end{array}$ \\
\hline 6 & \multirow{5}{*}{$\begin{array}{l}\text { Medium importance } \\
(30 \%)\end{array}$} & Team training & 0.088 & Teamwork \\
\hline 7 & & Physical strength & 0.075 & $\begin{array}{l}\text { Improvement of individual } \\
\text { tactics and skills }\end{array}$ \\
\hline 8 & & $\begin{array}{l}\text { Awareness of system } \\
\text { framework }\end{array}$ & 0.072 & Teamwork \\
\hline 9 & & Leadership and governing & 0.038 & Teamwork \\
\hline 10 & & Courage and discipline & 0.028 & Teamwork \\
\hline
\end{tabular}

\section{CONClusion AND SugGeSTIONS}

According to the special geographical features (near the mountain and by the river), mountain rescue, drowning rescue, diving rescue, and car accident rescue of Miaoli County, as well as the analysis of the current intensity of fire rescue training of Miaoli Government, this study aimed to explore the appropriateness and degree of importance and effectively improve the quality of fire rescue training.

\subsection{Conclusion}

Description of the decision-making items influencing the intensity of fire rescue training in Miaoli County:

1. Application of ropes: Four key points, namely, application of basic ropes, basic setup of ropes and time selection, setup of tight ropes, and knots.

2. Application of equipment: Proficiency of relevant rescue equipment and understanding of technical specifications of the equipment.

3. Skills: Skills in the basic courses of the rescue team, such as lowering of ropes, rope crossing, climbing ropes, and application of binodal ladder.

4. Special disaster rescue: Professional training of water rescue, surf rescue, boat rescue, torrent rescue, mountain rescue, fire rescue, and search-and-rescue, etc.

5. Safety awareness: Risk control and assessment and precautionary measures. Excluding or strengthening the possibilities of risk factors.

Rescue training has the highest requirements of physical strength, skills, and concentration of firefighters with danger. Miaoli County has mountains, sea, and reservoirs, so the rescue missions are diversified. Thus, training course planning shall emphasize professional courses like application of basic equipment, rescue tactics and skills and add other special courses appropriately such as mountain search-and-rescue, torrent rescue, diving training, safety awareness, and son on so that the firefighters of Miaoli County can develop skills in line with the disasters in Miaoli. The key influencing factors are inseparable. This study selected the best planning specifically for the training of the fire rescue team in Miaoli which should not be directly adopted to that of other regions. 


\subsection{Suggestions}

This study proposes the following suggestions:

1. More students shall be recruited so as to train more elite firefighters. The courses shall focus more on the improvement of individual rescue skills, so the students can pass the training with excellent rescue skills and become qualified firefighters.

2. Because of the diversified topography and geography of Miaoli County, the weight of special courses shall be increased. Long-term, continuous, and comprehensive rescue drill can be adopted. Training hours can be prolonged to meet the diversified disasters of Miaoli County if required.

3. More fire fighting coaches shall receive the courses like safety awareness and risk management. They shall make sure every student shall have the correct safety knowledge and risk factor assessment ability so as to reduce the casualty rate after training and on duty.

\section{REFERENCES}

[1] National Fire Agency. Name of regulation: Guidance for Municipal, County, and City Organs to Establish Fire Rescue Team (Revised on June 30, 2000)

[2] Li, C. T., 2005. Study on On-the-job Training of the Specialized Police Agencies-An Example of National Park Police Corps. Master's thesis, National Chengchi University.

[3] Chen, S. C., 2012. Study on Detection Method of Firefighter Physical Fitness and Physical Enhancement Module Effectiveness Evaluation. Master's thesis, Tungnan University.

[4] Chiang, W. Y., 1999. Training Study on Effectiveness Evaluation. Master's thesis, National Central University.

[5] Shang. S. H., 2010. Physical Fitness Effectiveness Evaluation of Fire Department Rescue Training-An Example of Taipei County Government Fire Bureau. Master's thesis, National Taipei University of Technology.

[6] Chen, S. C., 2015. Study on Injury Causes during Rescue Training for Firefighters and Relevant Precautions: Case Study on Rescue Training in New Taipei City. Master's thesis, China University of Science and Technology.

[7] Wu, T. E., Liu, H. H., Huang, K. C., \& Tsai, C. J., 2004. Analysis on Firefighters' Training and Physical Fitness Testing Results-A Case Study on the Lifesavers from Taipei Fire Department. Police Science Quarterly, 34-6.

[8] Wu, P. E., 2002. Sharing Human Resource Management-Theory, Procedure, and Practice. Taipei City. Hanlu Books.

[9] Liang, J. R., 2013. Study on Fire Rescue Training and Job Satisfaction. Master's thesis, National Chiao Tung University.

[10] Murry, J. W., \& Hammons, J. O., 1995. Delphi: A Versatile Methodology for Conducting Qualitative Research. The Review of Higher Education, 18 (4), 423-436.

[11] Saaty, T. L., 1990. The Analytic Hierarchy Process, RWS Publications, Pittsburgh, PA.

[12] Teng, C. Y. \& Tseng, K. H., 1989. The Connotation, Characteristics, and Application of AHP Volume I \& II. 